\title{
Interactions between a cushion plant (Azorella selago) and surface sediment transport on sub-Antarctic Marion Island
}

\author{
N.S. Haussmann ${ }^{\text {a, } *}$, M.A. McGeoch ${ }^{\text {b }}$, J.C. Boelhouwers ${ }^{c}$ \\ a Department of Conservation Ecology and Entomology, Stellenbosch University, Private Bag X1, Matieland 7602, South Africa \\ ${ }^{\mathrm{b}}$ DST-NRF Centre for Invasion Biology and Cape Research Centre, South African National Parks, P.O. Box 216, Steenberg 7947, South Africa \\ c Department of Geography, Geoinformatics and Meteorology, University of Pretoria, Pretoria, 0002, South Africa
}

\section{A R T I C L E I N F O}

\section{Article history:}

Received 5 August 2008

Received in revised form 28 November 2008

Accepted 2 December 2008

Available online $\mathrm{xxxx}$

\section{Keywords:}

Particle sorting

Azorella selago

Terrace formation

Needle ice

Sub-Antarctic

\begin{abstract}
A B S T R A C T
On sub-Antarctic Marion Island cushions of the dominant vascular plant species, Azorella selago, interact with the geomorphology of fellfield landscapes by affecting sediment distribution and ultimately terrace formation. Here, to understand the consequences of Azorella cushions for substrate movement and sorting, we quantified the size and shape of Azorella cushions and the grain size distribution of sediment surrounding these cushions, using a combination of image analysis approaches. Results show that as cushions become larger, they tend to become more elongated and grow more perpendicular to the slope. Mean and variance of grain size were greater upslope of Azorella cushions, while the number of particles was higher downslope of cushions, although these differences were not significant at all sites studied. Differences between upslope and downslope particle sizes were, however, not related to cushion elongation or growth angle as had been expected. The observed sediment partitioning is likely caused by a combination of frost-related sediment transport and Azorella cushions acting as sediment obstructions. Understanding these interactions between Azorella cushions and the landscape is especially important in the light of recent warming and drying on the island, as particle size affects soil properties such as water-holding capacity and frost susceptibility.
\end{abstract}

(c) 2008 Elsevier B.V. All rights reserved.

\section{Introduction}

By interacting with and changing their immediate surroundings, plants (especially pioneer species) play an important role in landscape evolution in severe environments (Heilbronn and Walton, 1984; Pérez, 1989; Chapin et al., 1994). For example, by providing protection and insulation (Pérez, 1989) and acting as physical barriers in sediment movement pathways (Pérez, 1987a), plants alter bare soil chemical and physical conditions, affecting soil frost conditions (Pérez, 1987b, 1989), slope stability (Heilbronn and Walton, 1984; Frenot et al., 1998) and ultimately sediment movement processes and patterns (Holness and Boelhouwers, 1998; Boelhouwers et al., 2000). Although plants affect their abiotic surroundings, plant spatial distributions and growth forms are also affected by the geomorphological conditions surrounding them, such as suitable, stable substrate, needed for seedling germination. In this regard, plant-landform interactions of pioneer plant species in periglacial environments are especially important, as pioneer plants colonise loose slopes and influence sediment movement and sorting (Huntley, 1972; Heilbronn and Walton, 1984; Frenot et al., 1998), thereby playing an important role in providing suitable substrates for colonisation by other plant species. The necessity of

\footnotetext{
* Corresponding author. Tel.: +27 743547463; fax: +27 218083304

E-mail address: nshau@sun.ac.za (N.S. Haussmann).
}

monitoring plant-landform interactions in periglacial regions has been recognised, especially in the light of global climate change (e.g. Cannone et al., 2004). Although geomorphological processes and landforms influence the way in which the biotic environment will function in a changing environment, plant growth forms will also influence the way in which landscapes respond to global climate change.

On sub-Antarctic Marion Island an important interaction exists between the geomorphology of fellfield landscapes and the dominant vascular plant species, Azorella selago. For example, by colonising loose and exposed substrates (Huntley, 1972; Frenot et al., 1998), these cushion plants affect slope stability and improve substrate nutrient and moisture status (Huntley, 1971; Holness, 2004; Smith and Mucina, 2006). Furthermore, Azorella cushions are considered to influence frost creep and other sediment movement processes and play an important role in the formation of terraces and lobes (Holness and Boelhouwers, 1998; Boelhouwers et al., 2003). Marion Island is experiencing rapid and significant large-scale climate change (Smith, 2002; Le Roux and McGeoch, 2008a) and a thorough understanding of these biogeomorphological interactions is thus especially important. A number of studies have examined the relationships between plants and the physical processes and landforms surrounding them in Arctic and temperate alpine regions (e.g. Sigafoos, 1952; Anderson and Bliss, 1998; Cannone et al., 2004); areas which experience permafrost or seasonal freezing. Parallel studies have also been conducted in diurnal 
frost environments, but these have mainly focussed on tropical alpine mountain systems (Mark et al., 2001; Pérez, 2002; Brancaleoni et al., 2003; Cavieres et al., 2007). Although mid-latitude marine environments, such as the islands of the sub-Antarctic, also experience diurnal frost cycles, these frost environments differ markedly from those of tropical alpine mountain systems. For example, on Marion Island, small, diurnal and seasonal temperature ranges of $1.9{ }^{\circ} \mathrm{C}$ and $3.6{ }^{\circ} \mathrm{C}$ respectively (Smith, 2002) are conducive to rapid transitions in freeze/ thaw cycle frequency and intensity under changing temperature regimes that render them especially sensitive to climate change (Boelhouwers, 2003; Boelhouwers et al., 2003).

In addition, most studies of biogeomorphological interactions in periglacial environments have looked at how geomorphological processes influence plant spatial distributions (Anderson and Bliss, 1998; Pérez, 2002), community assemblages (Kozłowska and Rączkowska, 2002; Cannone et al., 2004) or plant morphology in stressed environments (Jonasson and Callaghan, 1992). Comparatively few studies have considered the effects of plants on substrate movement and the resulting grain size sorting and distributions in diurnal frost environments. Notable exceptions are studies on vegetation-banked terrace formation on sub-Antarctic Macquarie Island (Taylor, 1955; Selkirk, 1998) as well as studies on needle ice activity in the Venezuelan Andes (Pérez, 1987a,b). These studies often found a downslope coarsening in grain size towards plants or rocks that act as physical obstructions in sediment movement pathways (Pérez, 1987a,b; Selkirk, 1998). Determining grain size and grain size distribution is important, because (1) these factors affect the inherent properties of the sediment (such as erosion and frost susceptibility), (2) they give an indication of the origin of the sediment and (3) they also determine the mechanisms by which the sediment can be transported (Goossens, 2008). Therefore, directional differences in grain size characteristics could lead to directional differences in erosion, needle ice activity and subsequent frost heave and creep, which in turn are partially responsible for driving plant growth patterns in fellfield-dominated areas (Lynch and Kirkpatrick, 1995). In addition, the particle size of substrates has been shown to affect seed entrapment (e.g. Chambers et al., 1991) and subsequent seedling establishment and survival (e.g. Jumpponen et al., 1999; Chambers, 2001; Kleier and Rundel, 2004). A. selago is widespread across the sub-Antarctic (Huntley, 1972; Frenot et al., 1993) and the genus Azorella is native not only to the Southern Ocean islands, but also to tropical alpine regions of South America (Martinez, 1993). As a consequence, grain size and grain size sorting around Azorella cushions are potentially important determinants of landscape evolution, not only on Marion Island, but across a far broader geographic range.

Previous studies have not examined the effect of $A$. selago cushions, with varying size and shape and growing at different angles with respect to slope, on sediment movement and grain size sorting. On Marion Island $A$. selago cushions are found in a variety of shapes including circular, elongated and irregular. Large cushions have been found to spread out laterally and coalesce, forming almost continuous carpets in some locations (Huntley, 1972; Mortimer et al., 2008). Plant cover patterns have demonstrated that established plants facilitate the presence of other plant species by providing protection against downslope moving particles (Le Roux and McGeoch, 2008b). In this regard, larger and more elongated cushions are expected to obstruct sediment particles moving downslope more than smaller or more rounded cushions. This is expected to result in larger differences in grain size characteristics between up- and downslope cushion sides for elongated cushions. Similarly, cushions growing at angles more perpendicular to the slope are expected to obstruct downslope moving particles more than cushions growing parallel to the slope. Furthermore, the shape of cushion plants in general has been shown to be related to cushion size, with small cushions being rounder and shapes becoming progressively irregular as the cushions grow (Pyšek and Liška, 1991). This relationship has also been observed for $A$. selago on
Marion Island (Huntley, 1972), although it has never been formally quantified.

Traditionally, grain size is determined through sieving, sedimentation experiments and direct measurement, depending on the size range of particles (Folk, 1966). These techniques all require taking a representative sample and subsequent physical analyses of the sample, and are, as a result, both time-consuming and destructive. As an alternative, photogrammetric techniques have been applied for the quantification of grain size parameters since at least the 1970s, especially in river channel hydraulics (Adams, 1979; Ibbeken and Schleyer, 1986; Whitman et al., 2003; Graham et al., 2005a). Many previous photogrammetric studies of sediment grain sizes have involved manually outlining sediment grains on the digital image (Ibbeken and Schleyer, 1986; Ibbeken et al., 1998; Whitman et al., 2003), although, more recently, the focus of photogrammetric studies has been on automating grain detection and data generation (Butler et al., 2001; Sime and Ferguson, 2003; Graham et al., 2005a). In protected, relatively undisturbed areas, such as Marion Island which has Special Nature Reserve conservation status, it is desirable to use techniques such as these photogrammetric methods as they minimise disturbance to the environment. Therefore, to increase our understanding of the two-way interactions of Azorella plants and substrate movement and sorting, we quantified the directionality in grain size distribution of sediment surrounding Azorella cushions of varying size and shape, using image analyses. We specifically examined (1) relationships between cushion size and elongation on flat and sloping terrains, (2) relationships between cushion elongation and growth directionality on flat and sloping terrains, (3) differences in grain size characteristics between up- and downslope cushion sides and (4) relationships between cushion characteristics and directional differences (up-and downslope of a cushion) in grain size characteristics. Finally, we highlight similarities and differences in plant-landform interactions between tropical alpine mountain systems and mid-latitude maritime environments, two distinct diurnal frost environments.

\section{Study area and site selection}

Marion Island ( $46^{\circ} 54^{\prime} \mathrm{S}, 37^{\circ} 45^{\prime} \mathrm{E}$ ), one of two islands constituting the Prince Edward Island Group, is located in the southern Indian Ocean (Fig. 1). The island constitutes the summit of a shield volcano and has an area of approximately $290 \mathrm{~km}^{2}$ (Verwoerd, 1971; De Villiers, 1976). Two lava successions, an older sequence of grey lava underneath a younger sequence of black lava, are found on the island (Verwoerd, 1971). Striated, grooved and smoothed features on older grey lava provide evidence of a period of glaciation in between the two lava successions (Verwoerd, 1971; Hall, 2004). The island has an exceptionally maritime climate, with a mean annual air temperature of just over $6{ }^{\circ} \mathrm{C}$ (Smith, 2002) and a mean annual soil temperature at the study sites of $4.7^{\circ} \mathrm{C}$ ( $5 \mathrm{~cm}$ depth) (Haussmann, unpublished data). Both annual and diurnal temperature ranges are low $\left(3.6\right.$ and $1.9^{\circ} \mathrm{C}$ respectively; Smith, 2002), giving rise to diurnal frost cycles (Holness, 2001a) and frequent needle ice formation (Boelhouwers et al., 2000, 2003; Holness, 2003). The average annual precipitation during the 1990s was just over 2000 mm (Le Roux and McGeoch, 2008a), with short-lived snow cover in the study area of c. 30 days per year (Holness, 2001a). Furthermore, a high degree of cloudiness and predominantly north-western gale force winds occur throughout the year (Schulze, 1971).

Sites for this study were selected from Tafelberg, on the eastern side of the island, at approximately $300 \mathrm{~m}$ a.s.l (Fig. 1). The Tafelberg area is underlain by pre-glacial grey basalts. Surface material consists of a matrix-supported, unsorted glacial till and experiences c. 60 diurnal frost cycles in the upper $5 \mathrm{~cm}$ of soil (Holness, 2001a; Boelhouwers et al., 2003). Frequent needle ice formation results in frost heave and creep of up to $20 \mathrm{~cm} \mathrm{a}^{-1}$ (Boelhouwers et al., 2000; Holness, 2001a; Boelhouwers et al., 2003; Holness, 2003). 


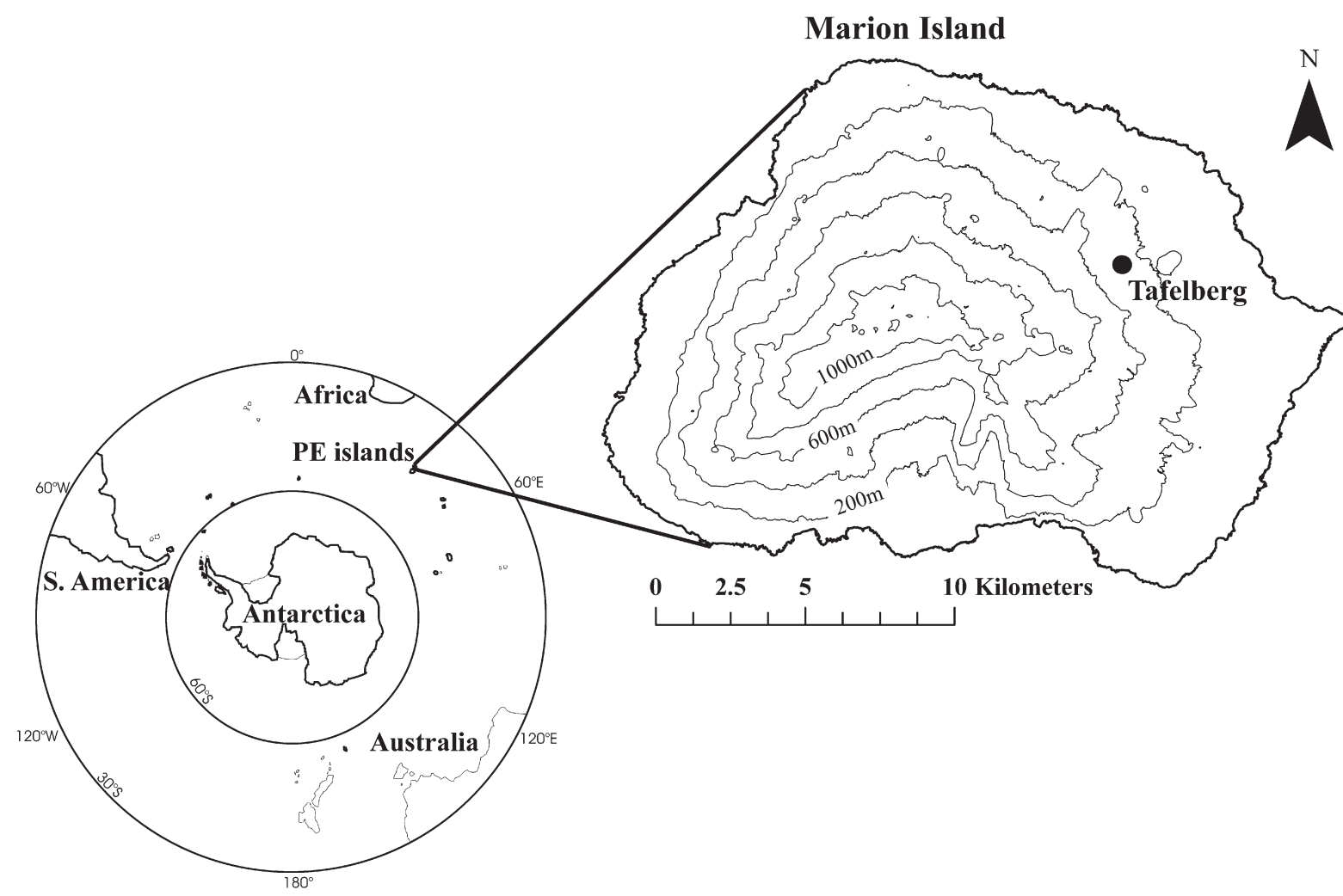

Fig. 1. Location of the PE (Prince Edward) islands within the sub-Antarctic and that of the study area, Tafelberg, on Marion Island. Contour interval is 200 m.

Three sites were selected within $300 \mathrm{~m}$ from one another, one from a relatively flat basin ( $4-5^{\circ}$ slope angle) (Fig. $2 \mathrm{a}$ ) and the other two from moderately sloping terrains ( $7-12^{\circ}$ slope angles for both sites), with easterly (Fig. 2b) and south-easterly (Fig. 2c) aspects respectively. These sites are referred to as the flat basin (FB), easterly slope (SE) and southeasterly slope (SSE). The geomorphology of the sites reflects the periglacial nature of the terrain. Relict solifluction lobes and terraces with risers of up to $0.5 \mathrm{~m}$ are present on sloping ground (see background slopes in Fig. 2a) (Holness and Boelhouwers, 1998; Boelhouwers et al., 2008). Upfreezing of clasts from the till cover is evident by their absence down to a depth of c. $20 \mathrm{~cm}$, and reflects a phase of deeper soil frost penetration than at present. Upfreezing and surface wash of fines explains the stony surface layer (Fig. 2). Present-day soil frost action results in patterned ground in the form of miniature sorted stripes with stripe widths of 5-10 cm (Boelhouwers et al., 2003). A. selago-banked terraces are common on sloping ground (foreground of Fig. 2a and whole of Fig. 2b). Distinction between currently active and relict terraces cannot be based on morphology alone, but terraces on the SE and SSE sites are considered of recent origin based on current mobility of surface materials (Holness, 2001a). On the flat basin site water ponding after intensive or long-duration rainfall suggests a shallow substrate and frequent surface runoff. This is further evidenced by the localised surface deposition of well-sorted fine gravel.

\section{Methods}

\subsection{Field procedure and image selection}

Photographs of $A$. selago cushions of various shapes and surrounding sediment were taken at the three sites, using a digital camera (Nikon D40, 28 mm, 6.4 megapixel). Each photograph contained one cushion and was taken vertically as far as possible to avoid image distortion. A ruler, with an arrow pointing in the downslope direction, was placed next to the cushions as a scale bar. Images in which individual grains could not be distinguished and images where the cushion outlines were not clear were excluded from analyses. Two image analysis approaches were used, depending on the quality of the image. Images suitable for digital image analyses were analysed using the Digital Gravelometer software 1.0, LUEL (Graham et al., 2005a,b). The digital image analysis dataset consisted mostly of round cushions, as these tended to be smaller and therefore easier to photograph vertically. These images were used to infer basic directionality patterns in grain size surrounding cushions. The second approach was used for images where the angle of photography was oblique and images that were too dark to distinguish all individual grains. These images were rejected for digital image analyses, but were considered suitable for a subjective visual estimation approach. These images were mostly of elongated cushions and were used to relate cushion properties, such as elongation and growth angle, to directional differences in grain size. For digital image analyses ten images were randomly selected from the flat basin and south-easterly slope, and all eight images from the easterly slope were also used. For the visual estimation approach eight photographs for the flat basin, 16 for the easterly slope and 12 for the south-easterly slope were available.

\subsection{Cushion size and shape analyses}

All selected images were used to analyse cushion size and shape. Lengths of the cushion major axis (largest diameter) and minor axis (longest axis perpendicular to the major axis) and cushion area were measured using SigmaScan Pro version 5.0, SPSS. Cushion major/ minor axis ratios were calculated as a measure of cushion elongation. The smallest angle between the major axis of the cushion and a line parallel to the downslope direction was measured and defined as the "growth angle" of the cushion. Analysis of Variance (ANOVA) was used to compare cushion characteristics between sites for the two datasets (digital analysis and visual estimation) separately. To determine the relationship between cushion elongation and size, we calculated Pearson correlation coefficients (for the two datasets combined) between the major/minor ratio and cushion area $(n=64)$. The same 

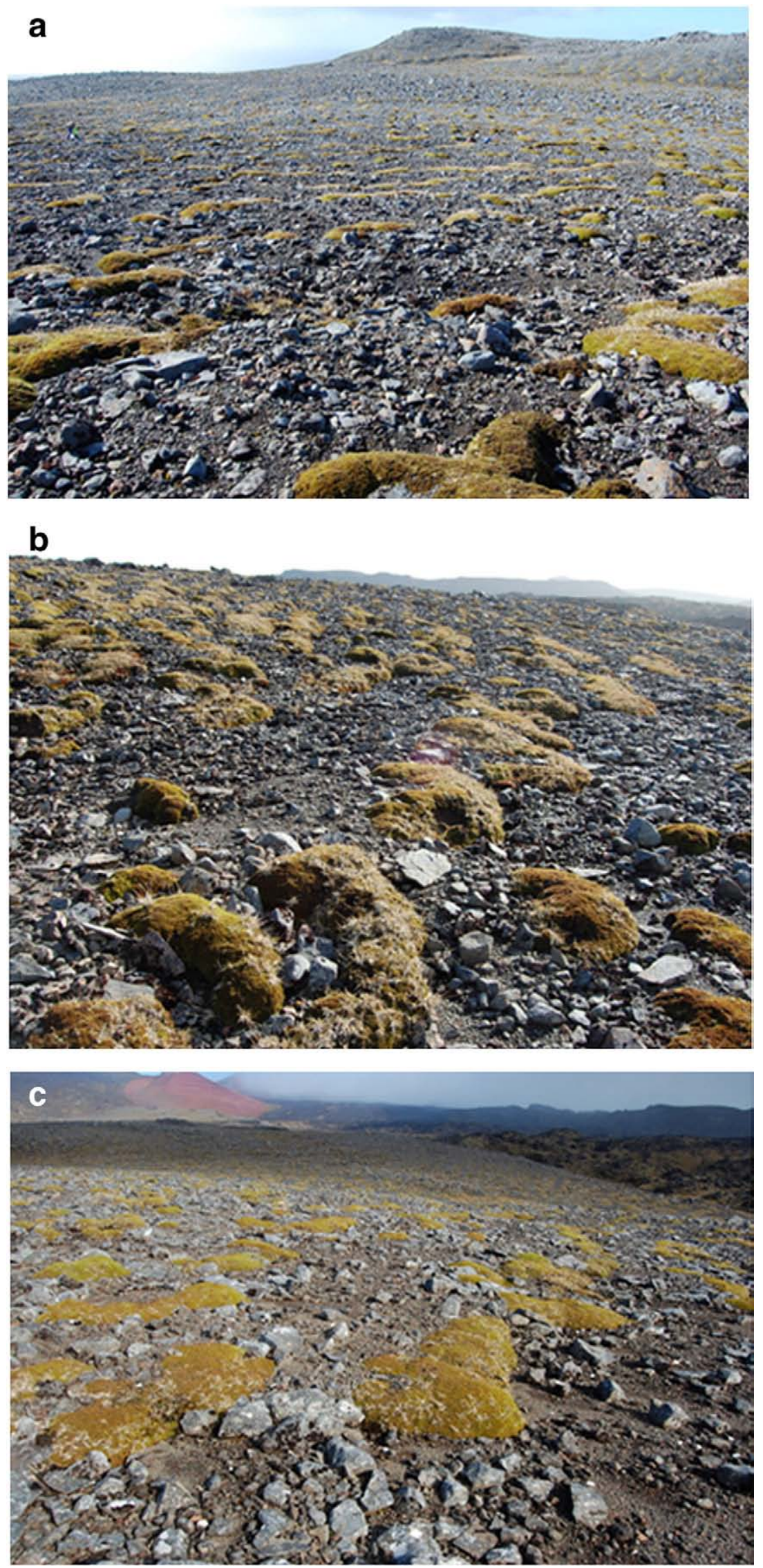

Fig. 2. Three sampling sites: (a) the flat basin (FB), (b) the slope with easterly aspect (SE) and (c) the slope with south-easterly aspect (SSE). 


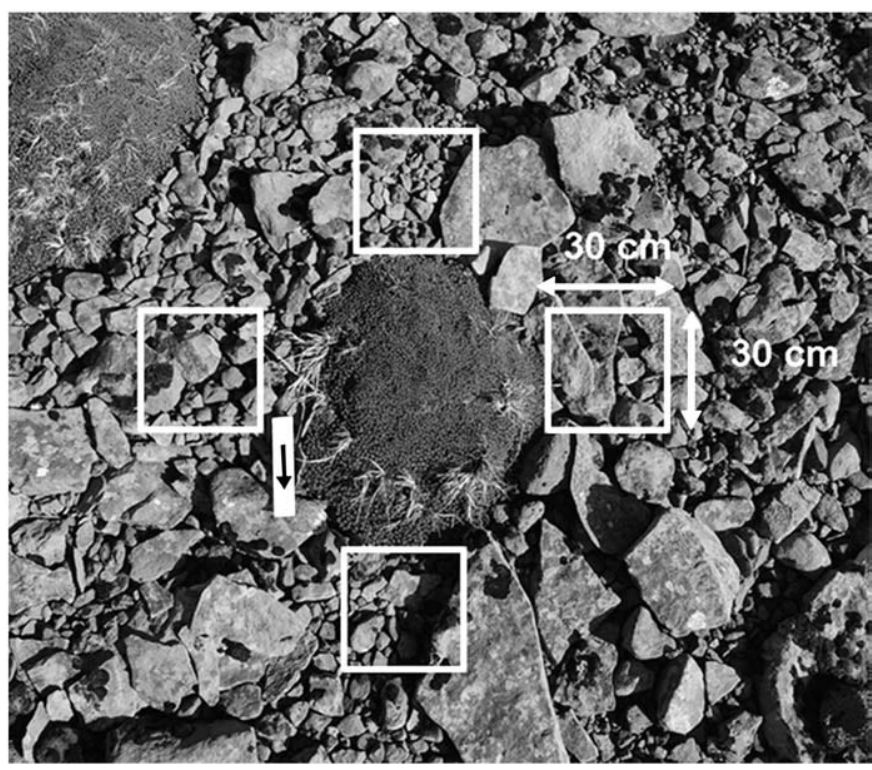

Fig. 3. Photograph of one of the Azorella cushions showing the cropped out squares on upslope, downslope, and left and right sides.

was done to determine relationships between cushion elongation and growth angle, using the major/minor ratio and angle.

\subsection{Digital image analyses procedure}

For each image, squares were cropped from the whole image on the upslope, downslope and remaining two opposing sides of the cushion, as close to the cushion edge as possible (Fig. 3). These sides are referred to as left and right, with upslope being at the top of the image. A $30 \times 30 \mathrm{~cm}$ square was deemed suitably large to pick up differences in grain size between squares. For some images squares of this size did not fit into the photograph, as the cushion was closer than $30 \mathrm{~cm}$ from the image edge. In this case a $15 \times 15 \mathrm{~cm}$ square was used.

A common problem with automated identification of sediment grains is uneven lighting and shading as a result of different elevations of particles (Graham et al., 2005b). The shadow/highlight function in Adobe Photoshop CS3 was used to adjust image shadow intensities and improve grain identification by the Digital Gravelometer. Image resolution was increased artificially from 120 to 720 pixels $\mathrm{cm}^{-1}$ using a bicubic resampling interpolation method in Adobe Photoshop CS3 to decrease the smallest detectable particle size from 12 to $2 \mathrm{~mm}$.
Particles with $b$-axes smaller than $2 \mathrm{~mm}$ were too small to be accurately detectable. To ensure that the resampled images were true to the original, each resampled image was carefully studied and compared to the original. Despite these adjustments, grain identification by the Digital Gravelometer was not completely satisfactory due to shadow effects and differences in texture and colour within individual grains. Therefore, the resulting black and white output images of the Digital Gravelometer were manually adjusted using Photoshop (Fig. 4). The manual adjustment of grain outlines and thereby the individual study of each image ensured accurate and most time-effective grain identification.

The $a$ - and $b$-axes of all identified grains, and the number of particles identified, were measured using SigmaScan Pro version 5.0, SPSS. All particle sizes reported are based on the $b$-axis value. The number of particles was corrected for the two different square sizes by dividing the number of particles in the $30 \times 30 \mathrm{~cm}$ squares by four. In addition, square size was included as a variable in the statistical analyses to assess and control for any effect thereof. To determine actual differences in grain sizes, common statistical measures were calculated for each square, including the graphical statistics of Folk and Ward (1957). To compare grain size characteristics between sites, generalised linear models (GLM) were used. Data were normally distributed after $\log _{10}$-transformation. One outlier was removed from the data set. ANOVA was used to identify differences in grain size characteristics between cushion sides at different sites.

\subsection{Visual estimation of particle sizes}

A $15 \times 15 \mathrm{~cm}$ square was cropped out of the upslope, downslope, and left and right sides of cushions. The percentage area covered by particles falling into each of seven different size classes was visually estimated using the following Wentworth size classes: 1) cobble, 2) very coarse gravel, 3) coarse gravel, 4) medium gravel, 5) fine gravel, 6) very fine gravel, and 7) $<2 \mathrm{~mm}$. Weighted mean particle sizes were calculated by multiplying the fraction of particles in each size class by the median mm value of the size class (Wentworth, 1922) and subsequently adding the values obtained for all size classes.

To determine whether particle size composition was related to cushion sides (upslope, downslope, and lateral), we used multivariate analysis on the visual estimation images (all three sites; $n=144$ images). Site was included as a co-variable. Left and right cushion sides were grouped together and renamed 'lateral' to simplify interpretation and because there was no a priori reason for differences in particle size composition between the two sides. The digital analysis supported this assumption. Sample heterogeneity and outliers were assessed through Detrended Correspondence Analysis (DCA) (Lepš and Šmilauer, 1999). As the DCA showed no single evident environmental gradient, a Canonical a

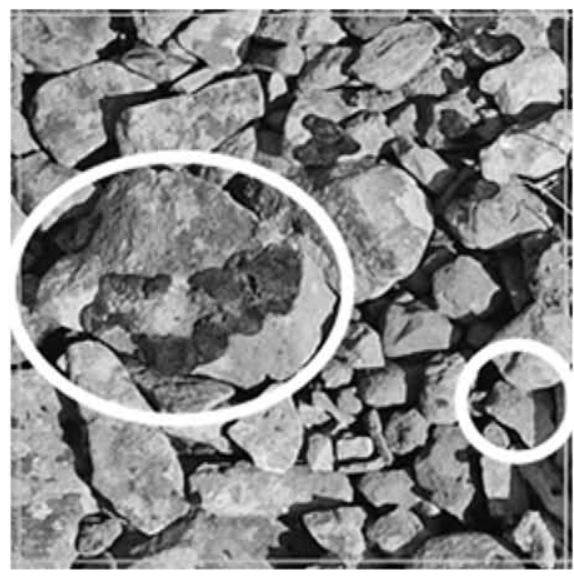

b

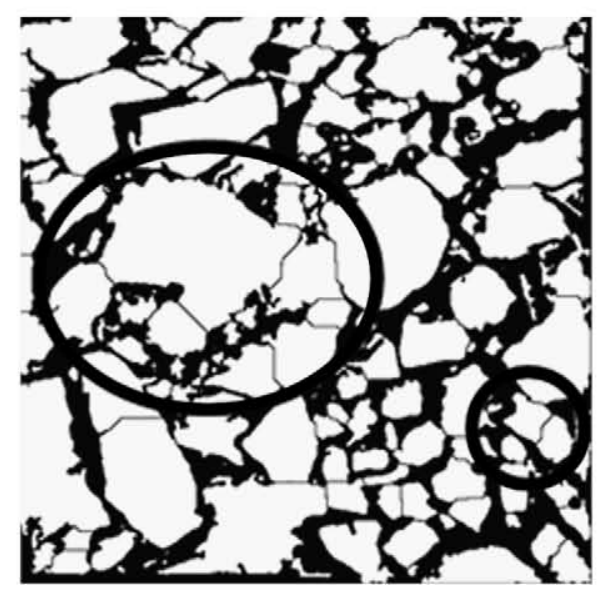

C

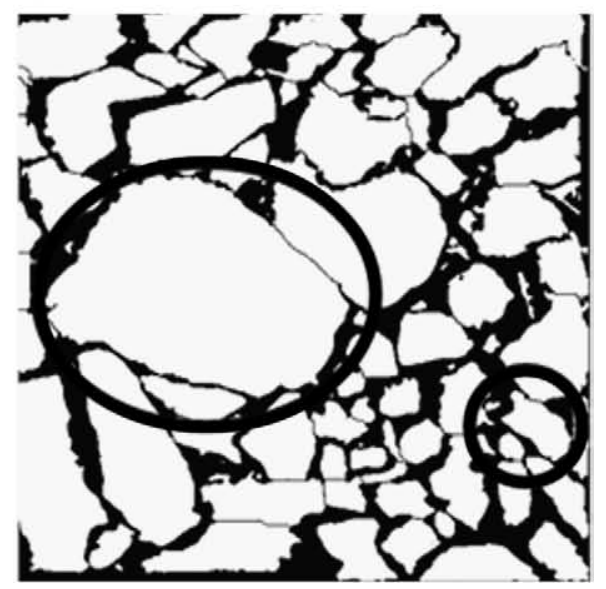

Fig. 4. Steps of the image analysis procedure, showing (a) the original image, (b) the results from the digital gravelometer and (c) the results after some manual corrections. 
Table 1

Cushion parameters across the three sites for the digital analyses dataset

\begin{tabular}{llll}
\hline & Site & & \\
\cline { 2 - 4 } & FB & SE & SSE \\
\hline Slope angle $\left(^{\circ}\right)$ & $4-5$ & $7-12$ & $7-12$ \\
Aspect & $\mathrm{n} / \mathrm{a}$ & East & South-east \\
Number of cushions & 10 & 8 & 10 \\
Major axis $(\mathrm{mm})$ & $662 \pm 57$ & $570 \pm 61$ & $610 \pm 46$ \\
& $(444-970)$ & $(328-906)$ & $(437-868)$ \\
Minor axis $(\mathrm{mm})$ & $550 \pm 52$ & $494 \pm 60$ & $500 \pm 28$ \\
& $(360-857)$ & $(231-753)$ & $(336-629)$ \\
Major/minor ratio & $1.21 \pm 0.04$ & $1.18 \pm 0.05$ & $1.21 \pm 0.03$ \\
& $(1.09-1.47)$ & $(1.03-1.42)$ & $(1.03-1.38)$ \\
Area $\left(\mathrm{mm}{ }^{2} \times 10^{5}\right)$ & $2.7 \pm 0.5$ & $2.1 \pm 0.5$ & $2.2 \pm 0.3$ \\
& $(1.1-5.8)$ & $(0.6-4.9)$ & $(1.1-3.7)$ \\
Growth angle $\left(^{\circ}\right)$ & $42.5 \pm 6.7$ & $47.9 \pm 8.2$ & $51.1 \pm 7.0$ \\
& $(14.8-80.1)$ & $(11.6-85.1)$ & $(21.5-82.4)$ \\
\end{tabular}

Values are means \pm s.e. Values in brackets indicate ranges. $\mathrm{FB}=$ flat basin, $\mathrm{SE}=$ easterly slope, SSE=south-easterly slope. No significant differences were found for these parameters between sites (ANOVA, $p<0.05$ )

Correspondence Analyses was justified (CCA) (Lepš and Šmilauer, 1999). The CCA was used to quantify the contribution of the environmental variables (cushion sides) to overall variation in particle size distribution using CANOCO 4.5. A Monte Carlo permutation test (1000 permutations, $p<0.05$, with variation inflation factors $<10$; Gross, 2003) with forward selection of environmental variables was used to determine which of the variables contributed significantly to explaining grain size composition (Lepš and Šmilauer, 1999). These CCA results were interpreted using a samples-by-environmental-variables biplot.

To determine whether differences between up- and downslope particle sizes changed with cushion elongation or growth angle, Pearson correlation coefficients were calculated using the differences between upslope and downslope particle sizes (up-down) and cushion major/minor ratio and angle $(n=34)$.

\section{Results}

\subsection{Cushion size and shape}

Cushion major axes ranged from approximately $330 \mathrm{~mm}$ to $2.3 \mathrm{~m}$, whereas cushion major/minor ratios ranged from just over 1 to almost 3 (Tables 1 and 2). Cushion growth angles ranged from almost parallel to the slope to almost perpendicular to the slope (Table 2). No significant differences were found in any of the cushion parameters between the three sites for the digital analysis dataset (all $p<0.05$ ). For the visual estimation dataset cushion major axis $(F=6.84, d f=2$, $p=0.003)$, minor axis $(F=8.73, d f=2, p<0.001)$ and area $(F=9.40, d f=2$, $p<0.001$ ) were significantly larger at the SE site than at the FB or SSE

Table 2

Cushion parameters across the three sites for the visual estimation dataset

\begin{tabular}{llll}
\hline & Site & \\
\cline { 2 - 4 } & FB & SE & SSE \\
\hline Number of cushions & 8 & 16 & 12 \\
Major axis $(\mathrm{mm})$ & $956 \pm 160^{\mathrm{a}}$ & $1476 \pm 120^{\mathrm{b}}$ & $992 \pm 60^{\mathrm{a}}$ \\
& $(519-1924)$ & $(868-2298)$ & $(532-1315)$ \\
Minor axis $(\mathrm{mm})$ & $555 \pm 56^{\mathrm{a}}$ & $712 \pm 42^{\mathrm{b}}$ & $489 \pm 27^{\mathrm{a}}$ \\
& $(327-816)$ & $(456-1032)$ & $(329-630)$ \\
Major/minor ratio & $1.69 \pm 0.17$ & $2.06 \pm 0.11$ & $2.03 \pm 0.08$ \\
& $(1.28-2.74)$ & $(1.55-2.83)$ & $(1.62-2.44)$ \\
Area $\left(\mathrm{mm}^{2} \times 10^{5}\right)$ & $3.8 \pm 0.9^{\mathrm{a}}$ & $7.3 \pm 0.9^{\mathrm{b}}$ & $3.5 \pm 0.4^{\mathrm{a}}$ \\
& $(1.3-9.5)$ & $(3.3-14.6)$ & $(1.4-5.9)$ \\
Growth angle $\left(^{\circ}\right)$ & $53.5 \pm 9.9$ & $53.4 \pm 5.2$ & $67.4 \pm 6.7$ \\
& $(11.0-89.7)$ & $(5.2-88.0)$ & $(7.7-89.8)$
\end{tabular}

Values are means \pm s.e. Values in brackets indicate ranges. $\mathrm{FB}=$ flat basin, $\mathrm{SE}=$ easterly slope, SSE = south-easterly slope. Different superscripts indicate significant differences between sites (ANOVA, $p<0.05$ ).

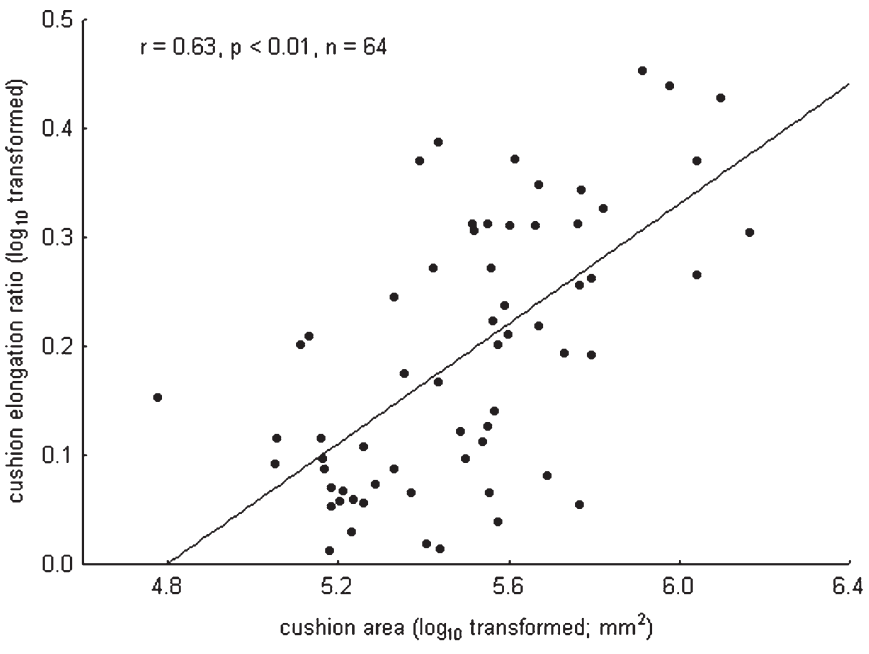

Fig. 5. Relationship between cushion area and the cushion elongation ratio for all cushions.

sites. The cushion major/minor ratio and growth angle did not differ significantly between any of the three sites (all $p<0.05$ ).

A significant $(p<0.05)$ positive correlation was found between cushion size and cushion elongation when grouping data together for all three sites, with larger cushions becoming more elongated (Fig. 5). This relationship was strongest for the SE site and weakest for the FB.

A weak, but significant $(r=0.32, p<0.05, n=64)$ positive correlation was found between cushion elongation and the angle that cushions were growing in relative to the slope, when grouping data together for all three sites (data not presented). However, when looking at the sites individually, this relationship was only significant for the SSE site.

\subsection{Digital image analyses procedure}

\subsubsection{Between-site variation}

Grains were in general in the range of very fine gravel $(-1$ to $-2 \varphi)$ to very coarse gravel $(-5$ to $-6 \varphi$ ) and poorly ( $\sigma=1$ to 2$)$ to moderately sorted ( $\sigma=0.5$ to 1 ) according to Folk and Ward's sorting index (Table 3). Most distributions had a negative skew indicating a tail of coarser particles. Kurtosis values were in the range platykurtic to very platykurtic, indicating that grains were relatively better sorted in the extremes of the distribution than in the central area. Mean grain size (Wald $X^{2}=42.316, d f=2, p<0.05$ ) and variance in grain size (Wald

Table 3

Grain size statistics across the three sites

\begin{tabular}{|c|c|c|c|c|}
\hline & & \multicolumn{3}{|l|}{ Site } \\
\hline & & $\overline{\mathrm{FB}}$ & SE & SSE \\
\hline $\begin{array}{l}\text { Number } \\
\text { of cushions }\end{array}$ & & 10 & 7 & 10 \\
\hline $\begin{array}{l}\text { Number } \\
\text { of particles }\end{array}$ & & $163.54 \pm 27.61^{\mathrm{a}}$ & $43.24 \pm 8.26^{\mathrm{b}}$ & $155.84 \pm 18.13^{a}$ \\
\hline \multirow[t]{3}{*}{ Grain size } & $b$-axis (mm) & $12.07 \pm 1.81^{\mathrm{a}}$ & $22.05 \pm 2.16^{\mathrm{b}}$ & $9.44 \pm 0.60^{a}$ \\
\hline & $b$-axis (F\&W) & $-2.69 \pm 0.16$ & $-3.71 \pm 0.84$ & $-2.72 \pm 0.07$ \\
\hline & F\&W category & Fine gravel & Medium gravel & Fine gravel \\
\hline \multirow[t]{3}{*}{ Sorting index } & s.t.d. (mm) & $14.93 \pm 2.16^{\mathrm{a}}$ & $22.66 \pm 2.55^{\mathrm{b}}$ & $9.93 \pm 0.86^{\mathrm{a}}$ \\
\hline & s.t.d. (F\&W) & $1.11 \pm 0.05$ & $1.35 \pm 0.16$ & $1.13 \pm 0.03$ \\
\hline & F\&W category & Poorly sorted & Poorly sorted & Poorly sorted \\
\hline \multirow[t]{3}{*}{ Skew } & Skew (mm) & $6.59 \pm 0.83^{\mathrm{a}}$ & $3.21 \pm 0.51^{\mathrm{b}}$ & $3.52 \pm 0.32^{\mathrm{b}}$ \\
\hline & Skew (F\&W) & $-0.31 \pm 0.04$ & $-0.06 \pm 0.03$ & $-0.21 \pm 0.02$ \\
\hline & F\&W category & Very negative & Nearly symmetrical & Negative \\
\hline \multirow[t]{3}{*}{ Kurtosis } & Kurtosis (mm) & $86.19 \pm 20.18^{a}$ & $22.59 \pm 9.66^{\mathrm{b}}$ & $20.70 \pm 4.62^{b}$ \\
\hline & Kurtosis (F\&W) & $0.68 \pm 0.02$ & $0.62 \pm 0.01$ & $0.63 \pm 0.01$ \\
\hline & F\&W category & Platykurtic & Very platykurtic & Very platykurtic \\
\hline
\end{tabular}

Values reported are across sampling unit (cropped squares) means \pm s.e. F\&W=Folk and Ward. FB= flat basin, $S E=$ easterly slope, $S S E=$ south-easterly slope. Different superscripts indicate significant differences between sites (GLM, $p<0.05$ ). 
$\left.X^{2}=26.579, d f=2, p<0.05\right)$ was significantly higher and the number of particles (Wald $X^{2}=42.183, d f=2, p<0.05$ ) was lower at the easterly slope than at the flat basin and the south-easterly slope (Table 3 ). Grain size distributions at the flat basin were found to be significantly more negatively skewed (Wald $X^{2}=23.0886, d f=2, p<0.05$ ) and the grains in the extremes were less well-sorted relative to the centre (Wald $X^{2}=24.4680, d f=2, p<0.05$ ) than at the other two sites (Table 3 ).

\subsubsection{Within-site variation}

At the FB mean grain size $(F(3,26)=3.48, p=0.03)$ and variance in grain size $(F(3,26)=4.26, p=0.01)$ was significantly greater upslope of Azorella cushions than downslope (Fig. 6a,b). By contrast, the number of particles $(F(3,26)=4.93, p=0.01)$ was greater on the downslope side of cushions than on the upslope (Fig. 6c). Grain sizes, variance and particle numbers on left and right cushion sides were intermediate to those on up- and downslope cushion sides (Fig. 6a-c). In addition, no significant differences in skew and kurtosis were found between cushion sides at this site (data not presented). Grid size, i.e. whether $15 \times 15 \mathrm{~cm}$ grids or $30 \times 30 \mathrm{~cm}$ grids were used, did not have a significant effect on either mean particle size or variance in particle size at this site. At the SE site downslope grains were found to be significantly smaller than both upslope and left side grains $(F(3,20)=4.14, p=0.02)$ (Fig. 6a). Again the size of squares used did not have an effect on mean particle size or variance in particle size. No significant differences were found in variance in grain size, particle numbers, skew or kurtosis between cushion sides at this site. No significant differences in mean grain sizes, variance, numbers of particles, skew or kurtosis were observed between cushion sides at the SSE site (Fig. 6a-c).

\subsection{Visual estimation of particle sizes}

A clear difference in particle size composition between the variables downslope and the other directions (upslope and lateral)
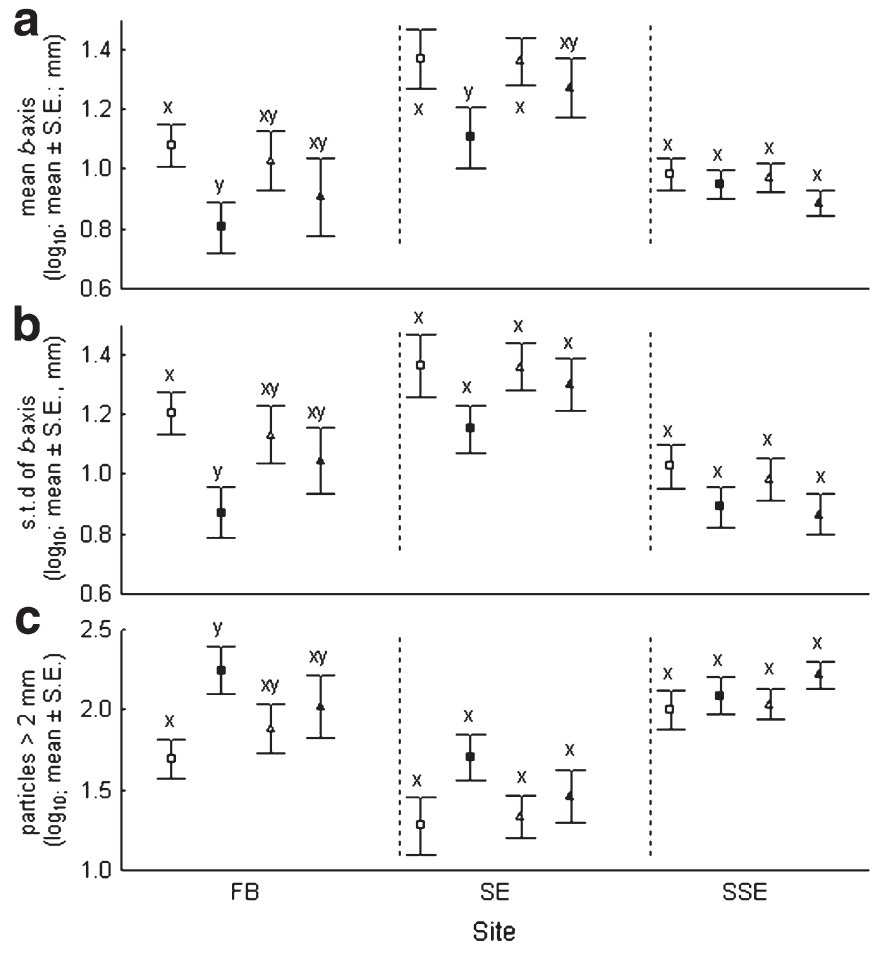

포 upslope 포 downslope 또 left 포 right

Fig. 6. Results of particle size analyses. (a) Mean $b$-axis of particles, (b) standard deviation of $b$-axis and (c) number of particles $>2 \mathrm{~mm}$. Graphs of skew and kurtosis are not shown. $\mathrm{FB}=$ flat basin, $\mathrm{SE}=$ easterly slope, $\mathrm{SSE}=$ south-easterly slope. Different lower case letters denote significant differences between cushion sides at respective sites $(p<0.05)$.

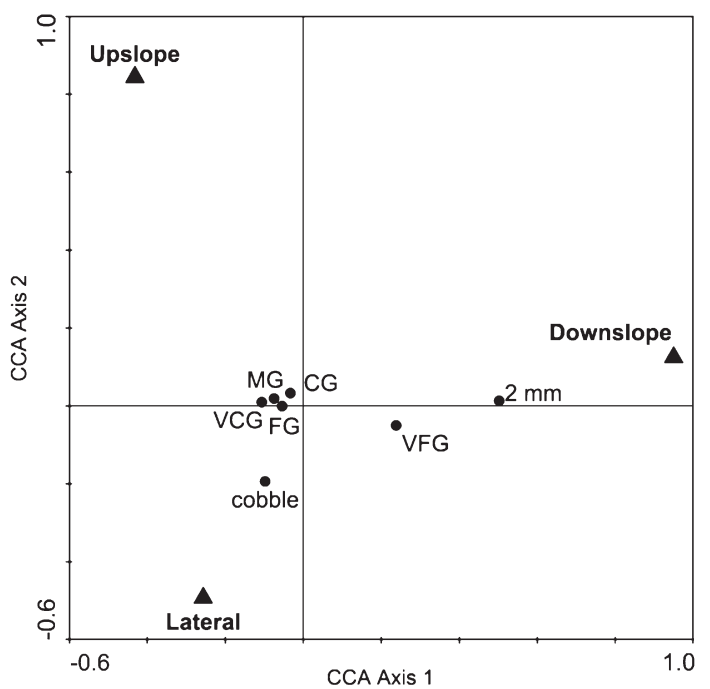

Fig. 7. Species-environment biplot from the CCA summarising the effects of cushion sides on particle size distribution after removing the effect of sites. VCG=very coarse gravel, $\mathrm{CG}=$ coarse gravel, $\mathrm{MG}=$ medium gravel, $\mathrm{FG}=$ fine gravel, $\mathrm{VFG}=$ very fine gravel, $2 \mathrm{~mm}=2 \mathrm{~mm}$ and smaller.

was apparent from their clear separation on the first axis of the CCA diagram (Fig. 7). After accounting for the effects of site, downslope was found to contribute significantly $(F=5.21, p=0.002)$ towards explaining grain size composition, being associated with the two smallest particle sizes ( $<2 \mathrm{~mm}$ and very fine gravel). However, upslope and lateral were not found to contribute significantly towards explaining particle size composition, i.e. particle size composition downslope of cushions differed significantly from those upslope and on lateral cushion sides, but upslope and lateral did not differ significantly from one another.

No significant correlations were found between directional differences (upslope and downslope) in grain size and the cushion major/ minor ratio $(r=-0.05, n=34, p=0.78)$ or cushion angle $(r=-0.04, n=34$, $p=0.82$ ) when grouping data for the three sites together. No significant correlations were found for individual sites either.

\section{Discussion}

The shape of cushion plant species has been related to cushion size, with small cushions being rounder and shapes becoming progressively irregular as the cushions grow (Pyšek and Liška, 1991). Although this relationship has also been observed for A. selago (Huntley, 1972), it has not been quantified yet. Our results on cushion size and shape suggest that as cushions become larger, they become more elongated, confirming general field observations. During a previous field survey, it was very hard to find either large, round cushions or small, elongated cushions. Rounder, smaller cushions are found growing at all angles to the slope. As cushions become larger and more elongated, growth is orientated mainly perpendicular to the slope. For example, all of the cushions with major/minor ratios larger than $2\left(\log _{10}\right.$ transformed value $=0.3$ ) were found at slope angles of $\geq 30^{\circ}$. Except for one cushion, with a major/minor ratio of 2.74, cushions at the FB site did not grow quite as elongate as cushions from the two slope sites, i.e. slope conditions apparently facilitate the growth of elongated cushions. An important distinction between the FB site and the slope sites is the poor drainage and high water table at the FB. The ground water table reached the ground surface repeatedly during the fieldwork period and water was often found to dam up behind Azorella cushions. In contrast, the sloping and micro-stepped topography at the two slope sites provides better local drainage, possibly facilitating directional cushion growth at these sites. This is particularly the case at terraces where coarser material has accumulated on upslope cushion sides. 
Wind exposure or directionality could also explain differences in cushion growth patterns between sites. Taylor (1955) emphasised the importance of wind in terrace formation on Macquarie Island. He found terraces to be orientated in such a way that vegetation always received least wind. Although the effect of wind on cushion growth was not formally assessed in our study, it can certainly not be excluded as a contributing factor to growth directionality patterns.

For all three sites particles on downslope cushion sides were smaller than those of upslope cushion sides (although this was only significant for the FB and SE site). This is also supported by the visual estimation dataset, where downslope is associated with smaller particle size classes than upslope or lateral cushion sides. Similarly, although not always significant, there were consistently more particles and better sorted particles on downslope cushion sides. Reports on the banking up of downslope moving particles on upslope sides of larger boulders as well as vegetation, which act as sediment obstructions, are numerous for periglacial environments (Pérez, 1987a; Holness and Boelhouwers, 1998; Selkirk, 1998; Mark et al., 2001; Holness, 2004). Movement of these particles is often ascribed to needle ice heaving, which lifts isolated stones from a matrix of finer particles, and subsequent downslope transportation of heaved particles by frost creep (Pérez, 1987a,b; Lawler, 1993; Holness, 2004). Needle ice is characteristic of brief, but frequent freeze-thaw cycles (Troll, 1958) and is favoured by soils with high silt content (Meentemeyer and Zippin, 1981), such as the gravely loams of fellfield habitats (Smith, 1977; Gremmen, 1981). Needle ice has also been identified as an important geomorphologic agent on Marion Island (Hall, 1979; Boelhouwers et al., 2003; Holness, 2003) and probably also plays a dominant role in facilitating downslope particle transportation through frost heave and creep in our study area. The vertical tilting of platy stones in our study area, often showing imbrication patterns, are direct indicators of the role of frost heave and creep (Benedict, 1970; Washburn, 1979; Holness and Boelhouwers, 1998). Preferential downslope movement of coarser sediment through frost creep (Benedict, 1976; Holness, 2001a; Holness, 2004) results in these clasts accumulating against Azorella cushions. This accumulation of coarser particles upslope of cushions results in a depletion of coarser clasts on downslope sides of cushions.

The decrease in particle sorting towards upslope cushion sides is a likely consequence of a negative feedback. As downslope transport slows down due to obstruction and material becomes coarser and thus better drained, frost penetration is no longer sufficient to sustain upheaving and subsequent frost creep, resulting in less sorted material. Contrary to frost creep-dominant movement, where the stones move faster than the surrounding soil matrix, solifluction, where the soil matrix moves and carries stones with it, results in less sorted particles (Benedict, 1970). This may in part explain the less sorted material at the SE site, compared to the other two sites. It is possible that slope movement at this site is presently, or was in the past, dominated by solifluction rather than needle ice creep. Solifluction requires frost penetration beyond the level for needle ice growth (deeper than approximately $5 \mathrm{~cm}$ at the altitude of our sites) and thus tends to displace a deeper layer of soil (Boelhouwers et al., 2003). This process results in larger steps than those formed through needle ice alone. These larger steps then create larger, protected micro-habitats which allow the growth of larger Azorella cushions (as seen at the SE site) and their lateral spreading along a pre-existing riser. A preferential occurrence of solifluction at the SE site is not readily explained under current climate conditions, but the terraces may be inactive forms, with secondary needle ice activity maintaining/modifying forms under the present climate, as observed elsewhere on the island at similar altitude (Holness and Boelhouwers, 1998).

Terrace formation is often found commencing across slopes in diurnal frost environments, such as the sub-Antarctic islands (Taylor, 1955; Holness and Boelhouwers, 1998; Holness, 2001b) and tropical alpine mountain systems (Pérez, 1992; Mark et al., 2001), often in association with vegetation (Holness and Boelhouwers, 1998; Selkirk, 1998). The exact mechanisms of terrace formation are still debated (Taylor, 1955; Löffler, 1983; Selkirk, 1998) and it is still unclear whether Azorella cushions exploit an already existing stable terrace riser or whether the riser develops in interaction with the laterally spreading Azorella cushion. In all likelihood, both scenarios are possible and may operate synergistically. Initial downslope changes in soil conditions, caused by grain size sorting through frost creep, or any other frost-protected location, may result in locally stable habitats for Azorella seedling establishment and lateral cushion growth on slopes. As the cushion grows, its role as a local obstacle to sediment displacement increases and an upslope-downslope soil textural differentiation develops. With time the cushions spread laterally along the terrace riser and coalesce with neighbouring cushions (Mortimer et al., 2008). Selkirk (1998) describes gravel chutes as areas in between terraces or cushions where stone transport is faster. Where the vegetation is able to grow faster than the stone encroachment, stable terraces are able to form. Similarly, Pérez (1987a) reports a higher rate of particle movement on the sides of large boulders, compared to up- or downslope sides of boulders. This accelerated particle movement on lateral cushion sides could possibly contribute towards cushion damage and turf exfoliation caused by needle ice (Pérez, 1992). These zones of instability and increased particle movement rates initially limit the lateral extent of terrace development. However, over time coarse material at the base of a chute starts blocking material, which imbricates against the larger less mobile material, creating a stable coarse slope segment.

Mechanisms of sediment sorting probably differ somewhat between the two slope sites and the FB. At the FB, a very uniform fine gravel deposit was often seen on downslope cushion sides, with upslope cushion sides containing larger, less uniform particles. Furthermore, although particle sorting was higher on downslope cushion sides than upslope cushion sides at all three sites, the FB was the only site where this difference was significant. Pérez (1987a, 1993) describes fine earth flags below rock dams in the Venezuelan Andes as "elongated downwards-tapering areas where coarse clasts are missing" and presents the phenomena as evidence of needle ice activity. Holness (2004) also reported this feature from cinder cones on Marion Island, again in an area dominated by needle ice activity. It is interesting to note that both authors report these features exclusively from slopes, whereas it was seen exclusively on the FB in our study site. A likely explanation is that sorting to the extent seen around these cushions at the FB is not the result of needle ice activity and frost creep alone. Frost creep by needle ice probably plays a dominant role in slowly moving frost heaved surface clasts across the low-angled local surface. However, the cushion (or large immobile block) barrier restricts clast movement and results in clast depletion downslope of the barrier. Surface wash across the exposed bare soil will then result in the washing-in of small, well-sorted gravel. Selkirk (1998) emphasises the importance of water for gravel movement and sorting around terraces on Macquarie Island. The importance of water transport on Marion Island, which receives more than double the amount of rainfall as Macquarie, should certainly not be overlooked. It is possible that on slopes the flow velocity is too high for the washed-in gravel particles to settle and therefore this feature is not found there. The poor drainage conditions and high water table at the FB compared to the slope sites further supports the notion that surface wash plays an important role in particle settling and grain size sorting at this site.

The correlation analyses did not pick up any relationships between cushion growth angle or shape and differences between up- and downslope particle sizes, as expected. The effect of cushion growth angle on differences between upslope and downslope particle sizes could not be distinguished from cushion shape and therefore size, as there were no elongated cushions growing parallel to the slope. Rounder, smaller cushions, growing parallel to slopes are apparently equally effective at trapping particles and causing grain size sorting as 
their larger, more elongated counterparts, which grow at angles more perpendicular to the slope.

The fact that downslope particles were consistently smaller than upslope particles has important implications for microenvironmental conditions, such as drainage, frost susceptibility and needle ice growth as well as cushion growth and die-back patterns. As stones get stacked they alter the microclimate, so that frost cannot penetrate through the coarse layer to the more fine, frost susceptible soil beneath, as a result of the superficial frost penetration of 5 to $10 \mathrm{~cm}$ at this altitude (Boelhouwers et al., 2003). Upslope particles will therefore be more stable and their heave rates smaller, whereas the potential for needle ice creep and surface disturbance will be larger on downslope cushion sides, creating a positive feedback to terrace development. Downslope cushion sides probably also develop a higher water retention capacity, as water can easily run through upslope blocks. This means that downslope sides have more potential for ice crystal growth as there is more water, increasing the potential for needle ice creep and surface disturbance on these sides. This in turn would facilitate terrace exfoliation on downslope cushion sides, as is often observed in the field. Rising temperatures and decreasing rainfall on Marion Island (Smith, 2002; Le Roux and McGeoch, 2008a) could lead to decreasing occurrences of needle ice and related sorting around cushions. On the other hand, predicted decreasing cloud cover (Smith and Steenkamp, 1990) and snow insulation could result in an increase in the number of freeze-thaw days and the spatial variability thereof (Boelhouwers, 2007) and increasing importance of needle-ice related sorting patterns. Therefore, the future implications of climate change for directional grain size sorting patterns and consequent sediment properties are not yet fully understood. To be able to predict landscape evolution and the future of grain size sorting patterns, sediment properties and terrace development in the light of a changing climate, continuing studies furthering our understanding of plant-landform interactions are essential.

\section{Conclusions}

As expected, A. selago cushions become more elongated and tend to grow more perpendicular to the slope as they become larger. As cushion growth commences, interactions with the surrounding sediment lead to sediment partitioning and terrace formation, a consequence of a combination of frost-related sediment transport and Azorella cushions acting as sediment obstructions. These results support the hypothesis that Azorella-banked terrace development is a self-organising system where interactions between Azorella cushions and sediment movement provide important feedbacks resulting in spatially organised landscape patterns. Furthermore, results of this study regarding the role of vegetation in sediment redistribution across diurnal soil frost environments are consistent with those from other maritime mid-latitude islands and high-altitude tropical mountains.

\section{Acknowledgements}

The South African National Research Foundation (NRF), South African National Antarctic Programme (SANAP) and the Swedish International Development Cooperation Agency (SIDA) are thanked for financial and logistic support. Jesse Kalwij and Ethel Phiri are thanked for their help with the multivariate analysis and GIS map respectively.

\section{References}

Adams, J., 1979. Gravel size analysis from photographs. American Society of Civil Engineers, Journal of the Hydraulics Division 105, 1247-1255.

Anderson, D.G., Bliss, L.C., 1998. Association of plant distribution patterns and microenvironments on patterned ground in a polar desert, Devon Island, N.W.T., Canada. Arctic and Alpine Research 30, 97-107.

Benedict, J.B., 1970. Downslope soil movement in a Colorado alpine region: rates, processes and climatic significance. Arctic and Alpine Research 2, 165-226.
Benedict, J.B., 1976. Frost creep and gelifluction features: a review. Quaternary Research $6,55-76$

Boelhouwers, J., 2003. Sensitivity and responses to climate change in the sub-Antarctic periglacial environment. International Permafrost Association: Eighth International Conference on Permafrost. A.A. Balkema, Rotterdam, pp. 67-71.

Boelhouwers, J., 2007. Plot- and slope-scale topographic and vegetation control on ground temperature spatial variability: synoptic-scale observations from Marion Island. South African National Antarctic Programme, P.I., Post-doc and Student Symposium. Centre for Invasion Biology, Stellenbosch.

Boelhouwers, J., Holness, S., Sumner, P., 2000. Geomorphological characteristics of small debris flows on Junior's Kop, Marion Island, maritime sub-Antarctic. Earth Surface Processes and Landforms 25, 341-352.

Boelhouwers, J., Holness, S., Sumner, P., 2003. The maritime Subantarctic: a distinct periglacial environment. Geomorphology 52, 39-55.

Boelhouwers, J.C., Meiklejohn, K.I., Holness, S.D., Hedding, D.W. 2008, Geology, geomorphology and climate change. In: Chown, S.L., Fröneman, P.W. (Eds.), The Prince Edward Islands: Land-Sea Interactions in a Changing Ecosystem. African Sun Media, Stellenbosch, pp. 67-96.

Brancaleoni, L., Strelin, J., Gerdol, R., 2003. Relationships between geomorphology and vegetation patterns in subantarctic Andean tundra of Tierra del Fuego. Polar Biology 26, 404-410.

Butler, J.B., Lane, S.N., Chandler, J.H., 2001. Automated extraction of grain-size data from gravel surfaces using digital image processing. Journal of Hydraulic Research 39, 519-529.

Cannone, N., Guglielmin, M., Gerdol, R., 2004. Relationships between vegetation patterns and periglacial landforms in northwestern Svalbard. Polar Biology 27, 562-571.

Cavieres, L.A., Badano, E.I., Sierra-Almeida, A., Molina-Montenegro, M.A., 2007. Microclimatic modifications of cushion plants and their consequences for seedling survival of native and non-native herbaceous species in the high Andes of central Chile. Arctic, Antarctic, and Alpine Research 39, 229-236.

Chambers, J.C., 2001. Pinus monophylla establishment in an expanding Pinus-Juniperus woodland: environmental conditions, facilitation and interacting factors. Journal of Vegetation Science 12, 27-40.

Chambers, J.C., MacMahon, J.A., Haefner, J.H., 1991. Seed entrapment in alpine ecosystems: effects of soil particle size and diaspore morphology. Ecology 72, 1668-1677.

Chapin, F.S., Walker, L.R., Fastie, C.L., Sharman, L.C., 1994. Mechanisms of primary succession following deglaciation at Glacier Bay, Alaska. Ecological Monographs 64, $149-175$.

De Villiers, A.F., 1976. Littoral ecology of Marion and Prince Edward Islands (Southern Ocean). South African Journal of Antarctic Research Supplement 1,1-40.

Folk, R.L., 1966. A review of grain-size parameters. Sedimentology 6, 73-93.

Folk, R.L., Ward, W.C., 1957. Brazos River Bar: a study in the significance of grain size parameters. Journal of Sedimentary Petrology 27, 3-26.

Frenot, Y., Gloaguen, J.C., Picot, G., Bougère, J., Benjamin, D., 1993. Azorella selago Hook. used to estimate glacier fluctuations and climatic history in the Kerguelen Islands over the last two centuries. Oecologia 95, 140-144.

Frenot, Y., Gloaguen, J.C., Cannavacciuolo, M., Bellido, A., 1998. Primary succession on glacier forelands in the subantarctic Kerguelen Islands. Journal of Vegetation Science 9, 75-84.

Goossens, D., 2008. Techniques to measure grain-size distributions of loamy sediments: a comparative study of ten instruments for wet analysis. Sedimentology 55, 65-96.

Graham, D.J., Reid, I., Rice, S.P., 2005a. Automated sizing of coarse-grained sediments: image-processing procedures. Mathematical Geology 37, 1-28.

Graham, D.J., Rice, S.P., Reid, I., 2005b. A transferable method for the automated grain sizing of river gravels. Water Resources Research 41, W07020.

Gremmen, N.J.M., 1981. The vegetation of the subantarctic islands Marion and Prince Edward. PhD thesis, Katholieke Universiteit Nijmegen, Nijmegen.

Gross, J., 2003. Variance inflation factors. R News 3, 13-15.

Hall, K., 1979. Sorted stripes orientated by wind action: some observations from subAntarctic Marion Island. Earth Surface Processes and Landforms 4, 281-289.

Hall, K., 2004. Quaternary Glaciations of the sub-Antarctic Islands. In: Ehlers, J., Gibbard, P.L. (Eds.), Quaternary Glaciations - Extent and Chronology, pt. III: South America, Asia, Africa, Australasia, Antarctica. Elsevier, Amsterdam, pp. 339-345.

Heilbronn, T.D., Walton, D.W.H., 1984. Plant colonization of actively sorted stone stripes in the subantarctic. Arctic and Alpine Research 16, 161-172.

Holness, S.D., 2001a. Periglacial slope processes, landforms and environment at Marion Island, maritime Subantarctic. PhD thesis, University of the Western Cape, Cape Town.

Holness, S.D., 2001b. The orientation of sorted stripes in the maritime subantarctic, Marion Island. Earth Surface Processes and Landforms 26, 77-89.

Holness, S.D., 2003. The periglacial record of Holocene environmental change, subantarctic Marion Island. Permafrost and Periglacial Processes 14, 69-74.

Holness, S.D., 2004. Sediment movement rates and processes on cinder cones in the maritime subantarctic (Marion Island). Earth Surface Processes and Landforms 29, 91-103.

Holness, S., Boelhouwers, J., 1998. Some observations on Holocene changes in periglacial activity at Long Ridge, Marion Island. South African Journal of Science 94, 399-403.

Huntley, B.J., 1971. Vegetation. In: van Zinderen Bakker, E.M., Winterbottom, J.M., Dyer, R.A. (Eds.), Marion and Prince Edward Islands: Report on the South African Biological and Geological Expeditions, 1965-1966. A.A. Balkema, Cape Town, pp. 98-160.

Huntley, B.J., 1972. Notes on the ecology of Azorella selago Hook. f. Journal of South African Botany 38, 103-113.

Ibbeken, H., Schleyer, R., 1986. Photo-sieving: a method for grain-size analysis of coarsegrained, unconsolidated bedding surfaces. Earth Surface Processes and Landforms $11,59-77$.

Ibbeken, H., Warnke, D.A., Diepenbroek, M., 1998. Granulometric study of the Hanaupah Fan, Death Valley, California. Earth Surface Processes and Landforms 23, 481-492. 
Jonasson, S., Callaghan, T.V., 1992. Root mechanical-properties related to disturbed and stressed habitats in the Arctic. New Phytologist 122, 179-186.

Jumpponen, A., Väre, H., Mattson, K.G., Ohtonen, R., Trappe, J.M., 1999. Characterization of 'safe sites' for pioneers in primary succession on recently deglaciated terrain. Journal of Ecology 87, 98-105.

Kleier, C., Rundel, P.W., 2004. Microsite requirements, population structure and growth of the cushion plant Azorella compacta in the tropical Chilean Andes. Austral Ecology 29, 461-470.

Kozłowska, A., Rączkowska, Z., 2002. Vegetation as a tool in the characterisation of geomorphological forms and processes: an example from the Abisko Mountains. Geografiska Annaler 84A, 233-244.

Lawler, D.M., 1993. Needle ice processes and sediment mobilization on river banks: the River Ilston, West Glamorgan, UK. Journal of Hydrology 150, 81-114.

Le Roux, P.C., McGeoch, M.A., 2008a. Changes in climate extremes, variability and signature on sub-Antarctic Marion Island. Climatic Change 86, 309-329.

Le Roux, P.C., McGeoch, M.A., 2008b. Spatial variation in plant interactions across a severity gradient in the sub-Antarctic. Oecologia 155, 831-844.

Lepš, J., Šmilauer, P., 1999. Multivariate Analysis of Ecological Data Using CANOCO. Cambridge University Press, Cambridge.

Löffler, E., 1983. Macquarie Island: a wind-molded natural landscape in the Subantarctic. Polarforschung 53, 59-74.

Lynch, A.J.J., Kirkpatrick, J.B., 1995. Pattern and process in alpine vegetation and landforms at Hill One, Southern Range, Tasmania. Australian Journal of Botany 43. 537-554.

Mark, A.F., Dickinson, K.J.M., Allen, J., Smith, R., West, C.J., 2001. Vegetation patterns, plant distribution and life forms across the alpine zone in southern Tierra del Fuego, Argentina. Austral Ecology 26, 423-440.

Martinez, S., 1993. Sinopsis del genero Azorella (Apiaceae, Hydrocotyloideae). Darwiniana 32, 171-184.

Meentemeyer, V., Zippin, J., 1981. Soil moisture and texture controls of selected parameters of needle ice growth. Earth Surface Processes and Landforms 6, 113-125.

Mortimer, E., McGeoch, M.A., Daniels, S.R., Jansen van Vuuren, B., 2008. Growth form and population genetic structure of Azorella selago on sub-Antarctic Marion Island. Antarctic Science 20, 381-390.

Pérez, F.L., 1987a. Downslope stone transport by needle ice in a high Andean area (Venezuela). Revue de Géomorphologie Dynamique 36, 33-51.

Pérez, F.L., 1987b. Needle-ice activity and the distribution of stem-rosette species in a Venezuelan Paramo. Arctic and Alpine Research 19, 135-153.

Pérez, F.L., 1989. Some effects of giant Andean stem-rosettes on ground microclimate, and their ecological significance. International Journal of Biometeorology 33, 131-135.

Pérez, F.L., 1992. Processes of turf exfoliation (rasenabschälung) in the high Venezuelan Andes. Zeitschrift für Geomorphologie 36, 81-106.
Pérez, F.L., 1993. Talus movement in the high equatorial Andes: a synthesis of ten years of data. Permafrost and Periglacial Processes 4, 199-215.

Pérez, F.L., 2002. Geobotanical relationship of Draba chionophila (Brassicaceae) rosettes and miniature frost-sorted stripes in the high equatorial Andes. Flora 197, 24-36.

Pyšek, P., Liška, J., 1991. Colonization of Sibbaldia tetrandra cushions on Alpine scree in the Pamiro-Alai mountains, Central Asia. Arctic and Alpine Research 23, 263-272.

Schulze, B.R., 1971. The climate of Marion Island. In: van Zinderen Bakker, E.M.S. Winterbottom, J.M., Dyer, R.A. (Eds.), Marion and Prince Edward Islands: Report on the South African biological and geological expeditions, 1965-1966. A.A. Balkema, Cape Town, pp. 16-31.

Selkirk, J.M., 1998. Active vegetation-banked terraces on Macquarie Island. Zeitschrift für Geomorphologie 42, 483-496.

Sigafoos, R.S., 1952. Frost action as a primary physical factor in Tundra plant communities. Ecology 33, 480-487.

Sime, L.C., Ferguson, R.I., 2003. Information on grain sizes in gravel-bed rivers by automated image analysis. Journal of Sedimentary Research 73, 630-636.

Smith, V.R., 1977. The chemical composition of Marion Island, soils, plants and vegetation. South African Journal of Antarctic Research 7, 28-39.

Smith, V.R., 2002. Climate change in the sub-Antarctic: an illustration from Marion Island. Climatic Change 52, 345-357.

Smith, V.R., Steenkamp, M., 1990. Climatic-change and its ecological implications at a sub-Antarctic island. Oecologia 85, 14-24.

Smith, V.R., Mucina, L., 2006. Vegetation of Marion and Prince Edward Islands. In: Mucina, L., Rutherford, M.C. (Eds.), Vegetation of South Africa, Lesotho and Swaziland. South African National Biodiversity Institute, Pretoria, pp. 698-723.

Taylor, B.W., 1955. Terrace formation on Macquarie Island. Journal of Ecology 43 $133-137$.

Troll, C., 1958. Structure, soils, solifluction, and frost climates of the earth. U.S. Army Snow Ice and Permafrost Research Establishment. Corps of Engineers, Wilmette, Illinois.

Verwoerd, W.J., 1971. Geology. In: van Zinderen Bakker, E.M.S., Winterbottom, J.M., Dyer R.A. (Eds.), Marion and Prince Edward Islands: report on the South African biological and geological expeditions, 1965-1966. A.A. Balkema, Cape Town, pp. 40-62.

Washburn, A.L., 1979. Geocryology, A Survey of Periglacial Processes and Environments. Edward Arnold, London.

Wentworth, C.K., 1922. A scale of grade and class terms for clastic sediments. Journal of Geology 30, 377-392.

Whitman, M.S., Moran, E.H., Ourso, R.T., 2003. Photographic techniques for characterising streambed particle sizes. Transactions of the American Fisheries Society 132 605-610. 